\section{RADIATION}

\section{Tissues ut Risk}

from a Correspondent

Subjects discussed at a meeting held in London on January 9 by the Society for Radiological Protection included malignancies arising from exposure of the bone and lung to radiation and recent data which have led to improved methods of assessing the radiation dose to those tissues from radionuclides deposited therein.

In his account of the origin, structure and radiosensitive areas of the bone, Dr J. F. Loutit (MRC Radiobiology Unit, Harwell) identified haematopoietic marrow, endosteum and cranial epithelia adherent to bone surfaces as the principal sites containing cells with a high proliferative potential and therefore at risk from radiation. $\mathrm{He}$ added that malignancies can and do arise elsewhere and cited as an example a high incidence of haemangioendotheliomas-tumours of the walls of the blood vessels--which he had recently observed in mice injected with ${ }^{90} \mathrm{Sr}$. The induction of tumours is related not only to the chemical behaviour and energy range of the radiation of bone seeking radionuclides but also to half life. Whereas ${ }^{224} \mathrm{Ra}$ with a short 3.8 day half life induces in man chiefly osteosarcomas, ${ }^{226} \mathrm{Ra}$ with a half life of 1,620 years induces both osteo and fibrosarcomas.

The relative radiotoxicities of ${ }^{224} \mathrm{Ra}$ and ${ }^{226} \mathrm{Ra}$ were considered by Dr G. W. Dolphin (National Radiological Protection Board, Harwell) who pointed out that per unit dose averaged over the skeleton, ${ }^{224} \mathrm{Ra}$, the shorter lived nuclide, induces a greater number of tumours than does ${ }^{226} \mathrm{Ra}$. One reason for this difference could be that the dose to cells at the bone surface relative to that averaged throughout the skeleton will be greater for ${ }^{224} \mathrm{Ra}$ than ${ }^{226} \mathrm{Ra}$ because the short-lived ${ }^{224} \mathrm{Ra}$ releases much of its $\alpha$ energy at the bone surface and ${ }^{226} \mathrm{Ra}$ most of its $\alpha$ energy after it has become distributed throughout the bone volume.

Methods developed by Professor F. W. Spiers (University of Leeds) for calculating the microdistribution of dose within the tissues of bone were described by Miss J. Whitwell (University of Leeds) and Mr P. Darley (Central Electricity Generating Board, Berkeley). These methods have already assisted greatly in the interpretation of the effects seen from radionuclides deposited in bone.

Dame Janet Vaughan (University of Oxford) identified the haematopoietic marrow as the tissue at greatest risk when the whole body or trunk is exposed to external radiation. The most common malignancy is leukaemia, but, as Dr Vaughan emphasized, the latent

period for leukaemia is short relative to that for other neoplasms such as osteosarcoma. These have been observed in groups which have been studied for 10 years or more after exposure. Such people are the ankylosing spondylitics and the children originally irradiated in utero. Leukaemia attributed to bomb radiations has been more in evidence in Hiroshima than in Nagasaki. Fast neutrons present in Hiroshima but not in Nagasaki have been incriminated. One effect of localized external irradiation in young children has been the development of exostoses, benign bony outgrowths, rather than osteosarcomas after radiation therapy for enlargement of the thymus.

In her review of the structure and metabolism of the lung Professor L. Reid (Institute of Diseases of the Chest, London) described as recent findings the presence of nerve endings in the alveoli and in the epithelium of the airways and the function of the brush borders in regulating the amount of fluid on the surface of the airways. She also defined the areas of deposition of particles of various sizes and also their clearance times. The longest, 60 to 120 days, is the normal clearance time from the alveoli, but this can be increased by tobacco smoke which immobilizes the cilia in the airways.

In spite of difficulties in obtaining relevant information concerning the incidence of radiation-induced lung cancer, Dr S. Rae (National Radiological Protection Board, Harwell) said that it is higher than normal in groups of haematite, fluospar and uranium miners exposed to radon. Cancers are predominantly of small undifferentiated cells in the hilar region of the lung and are more numerous on the right than on the left side. Some of the cancers may be attributable to the daughter products of radon.

\title{
Nuclear Steroid-receptor Complex
}

ENDOCRINOLOGISTS nowadays believe that steroid hormones are transported to the nuclei of target cells by specific cytoplasmic receptors which bind the hormone, presumably at the cell surface, and then migrate to the nucleus. Precisely how the hormone enters the nucleus and there alters the pattern of gene expression remains obscure, but, according to Liang and Tymoczko who write in Nature New Biology next week (February 14), the nuclei of prostate and uterine cells contain ribonucleoprotein particles respectively able to associate specifically with androgen and oestrogen-receptor complexes.

Liang and Tymoczko prepared ${ }^{3} \mathrm{H}$ hormone-receptor complexes from cytoplasmic extracts of rat prostate and calf uterine tissue. They also isolated from

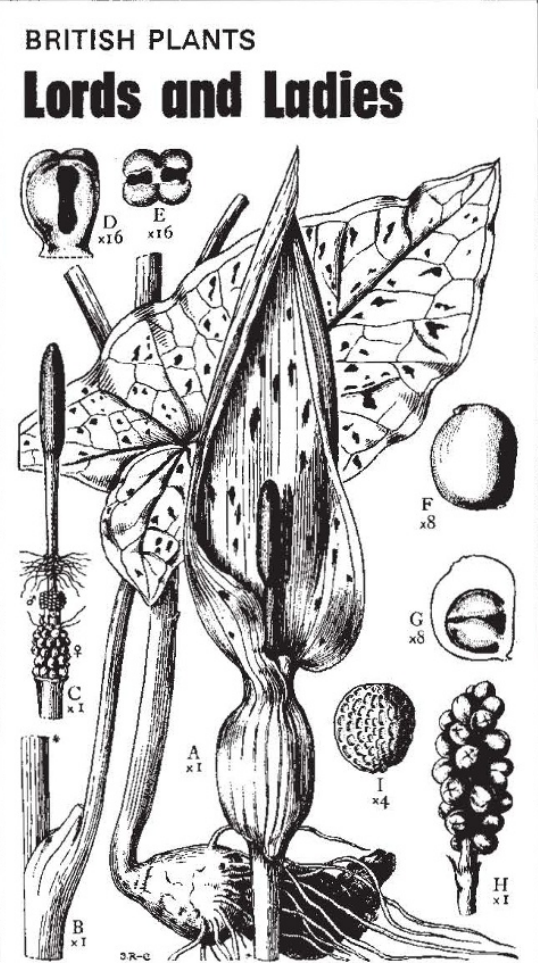

ThIS figure shows Stella RossCraig's drawing of Arum maculatum (commonly known as lords and ladies, cuckoo pint or wake robin) for the thirtieth and penultimate part of her authoritative series Drawings of British Plants (Bell, London, 1973). This new section covers the Juncaceae, Typhaceae, Sparganiaceae and Araceae.

Dr J. Vennart (MRC Radiobiology Unit, Harwell) said that the present recommendations of the International Commission on Radiological Protection in respect of maximum permissible concentrations were based on radiation the chromatin of the nuclei of these cells ribonucleoprotein particles which sediment at $30 \mathrm{~S}$ and $80 \mathrm{~S}$ respectively. In vitro these nuclear ribonucleoprotein particles specifically associate with the corresponding ${ }^{3} \mathrm{H}$ - hormone - receptor complexes. After heating or treatment with pancreatic ribonuclease, however, the nuclear particles lose this ability to bind hormone-receptor complex.

Liange and Tymoczko speculate that these nuclear particles may play some part in either effecting the entry of the hormone-receptor complex into the nucleus or mediating the action of the hormone on the genome. Whether these speculations are valid will no doubt emerge as these nuclear ribonucleoprotein particles are further characterized. 